\title{
Evaporation Behavior and Characterization of Eutectic Solvent and Ibuprofen Eutectic Solution
}

\author{
Thawatchai Phaechamud, ${ }^{1,4}$ Sarun Tuntarawongsa, ${ }^{2}$ and Purin Charoensuksai ${ }^{3}$
}

Received 20 September 2015; accepted 22 November 2015; published online 15 December 2015

\begin{abstract}
Liquid eutectic system of menthol and camphor has been reported as solvent and co-solvent for some drug delivery systems. However, surprisingly, the phase diagram of menthol-camphor eutectic has not been reported previously. The evaporation behavior, physicochemical, and thermal properties of this liquid eutectic and ibuprofen eutectic solution were characterized in this study. Differential scanning calorimetry (DSC) analysis indicated that a eutectic point of this system was near to 1:1 menthol/camphor and its eutectic temperature was $-1{ }^{\circ} \mathrm{C}$. The solubility of ibuprofen in this eutectic was $282.11 \pm$ $6.67 \mathrm{mg} \mathrm{mL}^{-1}$ and increased the drug aqueous solubility fourfold. The shift of wave number from Fourier transform infrared spectroscopy (FTIR) indicated the hydrogen bonding of each compound in eutectic mixture. The weight loss from thermogravimetric analysis of menthol and camphor related to the evaporation and sublimation, respectively. Menthol demonstrated a lower apparent sublimation rate than camphor, and the evaporation rate of eutectic solvent was lower than the sublimation rate of camphor but higher than the evaporation of menthol. The evaporation rate of the ibuprofen eutectic solution was lower than that of the eutectic solvent because ibuprofen did not sublimate. This eutectic solvent prolonged the ibuprofen release with diffusion control. Thus, the beneficial information for thermal behavior and related properties of eutectic solvent comprising menthol-camphor and ibuprofen eutectic solution was attained successfully. The rather low evaporation of eutectic mixture will be beneficial for investigation and tracking the mechanism of transformation from nanoemulsion into nanosuspension in the further study using eutectic as oil phase.
\end{abstract}

KEY WORDS: camphor; eutectic solvent; evaporation behavior; ibuprofen; menthol; phase diagram.

\section{INTRODUCTION}

The eutectic system is a mixture which the melting points of its components decrease because the total entropy of system increases $(1,2)$. Eutectic systems have been applied in pharmaceuticals to increase the drug solubility, permeation, and absorption (3-6). They have been used as an oil phase in an emulsion system (7) and the deep eutectic solvents (DESs) (8-11). Small-molecule compounds were used as eutectic compounds such as phenol (12). menthol $(4,6,13,14)$. menthone, cineole, limonene, thymol (4). salol $(3,15)$. and camphor $(16,17)$. Typically, the eutectic phenomena relate to hydrogen bonding between compounds $(4,12)$. Menthol has generally been used as a eutectic component exhibiting pharmaceutical actions such as local anesthetics, analgesics, antipruritics (18). and antimicrobials (19). Moreover, menthol is a permeation enhancer (18). which forms a liquid eutectic at room

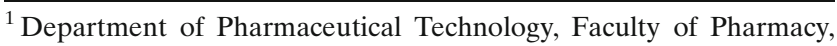
Silpakorn University, Nakorn Pathom, 73000, Thailand.

${ }^{2}$ Pharmaceutical Intelligence Unit Prachote Plengwittaya, Faculty of Pharmacy, Silpakorn University, Nakorn Pathom, 73000, Thailand.

${ }^{3}$ Department of Biopharmacy, Faculty of Pharmacy, Silpakorn University, Nakorn Pathom, 73000, Thailand.

${ }^{4}$ To whom correspondence should be addressed. (e-mail: tphaechamud011@yahoo.com)
}

temperature with many sublimate compounds such as camphor and borneol $(4,6,13,14,17)$. Menthol was able to form liquid eutectic as single phase at room temperature with camphor in the ratio of 8:2, 7:3, 6:4, and 5:5 whereas menthol and borneol in the ratio of 8:2 and 7:3 and menthol and $N$-ethyl-5methyl-2-(1-methylethyl) cyclohexanecarboxamide (WS-3) in the ratio of $6: 4$ and 1:1. However, menthol/camphor eutectic mixture exhibited the lower viscosity than that of the others (17). Menthol/camphor eutectic mixture was used as solvent for dispersing low-dose drug such as captopril for homogenous drug content uniformity in capsule and tablet which an ex vivo drug permeation through rat ileum was faster and increased (20).

Typically, thermal behaviors are major properties of the eutectic phenomenon; therefore, the differential scanning calorimetry (DSC) technique was used as the main technique to investigate this phenomenon. A simple phase diagram was created using DSC data to investigate the eutectic point and eutectic temperature $(3,4,12)$. Surprisingly, the evaporation behavior and the phase diagram of eutectic mixture of menthol-camphor have not been reported previously. Therefore, thermogravimetric analysis (TGA) and evaporating rate measurement conducted using gas chromatography were employed to evaluate the evaporation 
behavior of eutectic mixture in this study. Fourier transform infrared spectroscopy (FTIR) has been used typically to detect the interaction between compounds (12). thus, it was used to detect the hydrogen formation in eutectic mixture.

Ibuprofen has been used as a model drug in eutectic research such as ibuprofen liquid suppositories (6) and liquid transdermal delivery (4). Moreover, ibuprofen solution in eutectic system could be applied for emulgel system (21) and suspension preparation by emulsion solvent evaporation method (22). Recently, the therapeutic DES was used to prepare the ibuprofen particle using supercritical fluid technology (23).

In this research, the evaporation behavior and basic characterization of eutectic solvent and its drug solution were investigated. The DSC and TGA techniques were used for thermal behavior characterization. The chemical interaction was investigated by FTIR. Evaporation of the eutectic solvent was investigated in terms of rate and ratio of evaporation. The released kinetic of drug from the eutectic solution was also investigated.

\section{MATERIALS AND METHODS}

\section{Materials}

Menthol, camphor, and ibuprofen were purchased from P. C. Drug Center Co. Ltd., Bangkok, Thailand. Phosphoric acid $85 \%$ was purchased from Merck KGaA, Darmstadt, Germany, and acetonitrile was purchased from V.S. Chem House, Bangkok, Thailand. Potassium dihydrogen phosphate and sodium hydroxide were purchased from QReC, New Zealand, and used as received.

\section{Preparation of Eutectic Solvent}

Menthol (M) and camphor (C) were mixed in ratios of 1:9, 2:8, 3:7, 4:6, 1:1, 6:4, 7:3, 8:2, and 9:1 menthol/camphor $(\mathrm{M} / \mathrm{C})$ in glass-tight containers and continuously stirred on a magnetic stirrer at room temperature overnight. The eutectic systems which completely melted as liquid were investigated for viscosity and rheology using a Brookfield viscometer (DV-III Ultra Programmable Rheometer, Brookfield Engineering Laboratories, Inc., Middleboro, USA) using cone-and-plate geometry with a cone no. 40 $(n=3)$. One of the liquid eutectics was selected as the eutectic solvent. The lowest viscosity was chosen as selection criteria; thus, the good solvent should exhibit low viscosity that able to load other substances with high concentration.

\section{Phase Diagram of M/C Eutectic System}

Phase diagram of eutectic system was created from the DSC data of menthol, camphor, and their combinations. DSC thermograms of menthol, camphor, and the eutectic systems at ratios of 1:9 to 9:1 M/C were investigated using DSC (Pyris Sapphire DSC, Standard 115V, PerkinElmer Instruments, Japan). Analyzing temperature was set at the ranges of -20 to $200^{\circ} \mathrm{C}$. The simple phase diagram of menthol and camphor eutectic system was demonstrated as temperature of endothermic peak and amount of menthol in eutectic as previously reported (4). The eutectic point is the ratio in which a single melting point of liquid eutectic is obtained, and this melting point is the eutectic temperature, but when other two melting points are obtained, the first one is the eutectic temperature and the second is the melting peak of excess solid eutectic compound (24).

\section{Solubility Study of Ibuprofen and Ibuprofen Eutectic Solution}

The excess amount of ibuprofen was dissolved in the selected eutectic solvent and distilled water separately; then, the supernatant of saturated systems was collected to measure the drug solubility amount at room temperature $(n=3)$ using high-performance liquid chromatography (HPLC) with the ultraviolet (UV) detection (Agilent 1100 Series, Agilent Technologies, USA). The column was a C18 PEP column $\left(\mathrm{ACE}^{\circledR}\right)$. The mobile phase consisted of acetonitrile and $0.01 \mathrm{M}$ phosphoric acid 1:1 $v / v$. The flow rate was $1 \mathrm{~mL} \mathrm{~min}{ }^{-1}$, and the detection wavelength was $264 \mathrm{~nm}$. The injected volume was $20 \mu \mathrm{L}$. All the operations were carried out at room temperature. In addition, the ibuprofen eutectic solution was evaluated for the drug solubility in distilled water at ambient condition. Ibuprofen eutectic solution was added in water and continuously stirred by a magnetic stirrer in tight container for 1 week. The water part was sampled and filtrated through a $0.45-\mu \mathrm{m}$ syringe filter. The amount of solubilized ibuprofen in the water from eutectic mixture was measured using HPLC with the above-described method $(n=3)$.

\section{FTIR-HATR Analysis}

The interaction of eutectic system was investigated using a FTIR spectrophotometer (Nicolet 4700, Thermo Electron Corporation, Madison, USA). Menthol, camphor, and ibuprofen were evaluated using potassium bromide $(\mathrm{KBr})$ disk method. The eutectic system at ratios of $1: 9$ to $9: 1 \mathrm{M} / \mathrm{C}$ and ibuprofen eutectic solution were evaluated using a smart multi-bounce horizontal attenuated total reflection (HATR) combo kit set with a zinc selenide Avatar trough plate at $45^{\circ}$ (25).

\section{Thermal Analysis}

The samples were investigated for thermal behavior by DSC (Pyris Sapphire DSC, Standard 115V, PerkinElmer Instruments, Japan). The measurement temperature was set within the ranges of -20 to $200^{\circ} \mathrm{C}$ with a heating rate of $10^{\circ} \mathrm{C} \mathrm{m^{-1 }}$. Weight changes under heating condition with open system were investigated using a TGA (Pyris/TGA, PerkinElmer, USA). The experiment was carried out in the temperature ranges of 30 to $500^{\circ} \mathrm{C}$ at a heating rate of $10^{\circ} \mathrm{C} \mathrm{min}^{-1}$ in air atmosphere.

\section{Sublimation or Evaporation Rates}

The evaporation or sublimation rates of the eutectic system or solid components were investigated at 35, 45, 55, 65, 75, and $85^{\circ} \mathrm{C}$. Each sample with an accurate weight of $10 \mathrm{~g}$ as W1 was weighed in a cylindrical glass bottle (W2 with diameter $2.6 \mathrm{~cm}$ and cross-sectional area $5.30 \mathrm{~cm}^{2}$ ) and placed into a hot 
air oven to obtain the desired condition. Each sample was weighed every hour as Wt. The weight loss at the different times was calculated using $[(\mathrm{W} 1+\mathrm{W} 2)-\mathrm{Wt}]$. The correlation of weight loss $(y)$ and time $(x)$ was plotted as linear equation which slope of each equation was the weight loss rate. The evaporation and sublimation rates were calculated as weight loss rate per unit area $\left(\mathrm{mg} \mathrm{h}^{-1} \mathrm{~cm}^{-2}\right)(n=3)$.

\section{Evaporation Rate of $M$ and $C$ from Eutectic Solvent}

A 3-g eutectic solvent was accurately weighed $\left(W_{0}\right)$ and placed into a $50-\mathrm{mL}$ beaker with an internal diameter of $4 \mathrm{~cm}$ and placed into a hot air oven at $45^{\circ} \mathrm{C}$. The amounts of menthol and camphor ( $W_{\mathrm{Mt}}$ and $W_{\mathrm{Ct}}$, respectively) were determined at 8-h intervals for 2 days using gas chromatography (GC). The amounts of menthol and camphor were analyzed using a modified GC method (26) with validation by the 6890N GC network system (Agilent Technologies, USA). The GC column was polyethylene glycol (PEG) stationary phase (HP-Innowax, $30 \mathrm{~m}, 0.32 \mathrm{~mm}, 0.25 \mu \mathrm{m}$, and 7-in. cage, Agilent, J\&W Scientific, USA) with a flame ionization detector (FID) at $250^{\circ} \mathrm{C}$ (hydrogen $\left(\mathrm{H}_{2}\right)$ flow $30 \mathrm{~mL} \mathrm{~min}^{-1}$, air flow $350 \mathrm{~mL} \mathrm{~min}^{-1}$, and makeup gas (nitrogen, $\mathrm{N}_{2}$ ) flow $30 \mathrm{~mL} \min ^{-1}$ ). The inlet temperature was $250^{\circ} \mathrm{C}$, split ratio 47.6:1. Helium (He) was used as the carrier gas at a flow rate of $1.2 \mathrm{~mL} \mathrm{~min}^{-1}$. The oven temperature was set initially at $50^{\circ} \mathrm{C}$ and increased to $200^{\circ} \mathrm{C}$ with a heating rate of $15^{\circ} \mathrm{C} \mathrm{min} \mathrm{m}^{-1}$ and a hold of $10 \mathrm{~min}$ (total time was $20 \mathrm{~min}$ ). The sample $(1 \mu \mathrm{L})$ was injected with a $7683 \mathrm{~B}$ series injector (Agilent Technologies, USA). The rate of weight loss $\left(\mathrm{mg} \mathrm{h}^{-1}\right)$ was calculated from the slope of weight loss of menthol or camphor $\left(\left(W_{0} / 2\right)-W_{\mathrm{Mt}}\right)$ or $\left(W_{0} / 2\right)-W_{\mathrm{Ct}}$, respectively) and time (h). The evaporation and sublimation rates were reported as weight loss rate per unit area $\left(\mathrm{mg} \mathrm{h}^{-1} \mathrm{~cm}^{-2}\right)(n=3)$.

\section{Release Kinetic of Ibuprofen from Eutectic Solution}

Ibuprofen was dissolved in eutectic solvent at concentration of $10 \% \mathrm{w} / \mathrm{w}$. The in vitro drug release was investigated by dialysis tube method. The 1-g eutectic drug delivery system was added into the dialysis tube with molecular weight cutoff (MWCO) 6-8000 (Spectra/Por dialysis membrane, Spectrum Laboratories, Inc., CA, USA), and the drug release using shaking incubator (NB-205, NBiotek, Korea) at $50 \mathrm{rpm}$ and $37 \pm 0.5^{\circ} \mathrm{C}$ was investigated? The 100-mL phosphate buffer solution, $\mathrm{pH} 6.8$, was used as release medium. The sampling time intervals were $5,10,15$, 30,60 , and $90 \mathrm{~min}$ then $2,3,4,6,8,12,16,24,32,44,56,68$, $80,124,128$, and $152 \mathrm{~h}$, respectively. The sampling volume was $5 \mathrm{~mL}$ through the syringe filter $0.22 \mu \mathrm{m}$, and equal volume of a fresh medium was replaced. The amount of drug released at specific time interval was measured by HPLC method $(n=3)$, and the least square fitting the experimental released data to the mathematical expressions (power law, first order, Higuchi's, and zero order) was carried out using a nonlinear computer program, Scientist for Windows, version 2.1 (MicroMath Scientific Software, Salt Lake City, UT, USA). The coefficient of determination $\left(r^{2}\right)$ was used to indicate the degree of curve fitting. Goodness of fit was also evaluated using the model selection criterion (msc) (27).

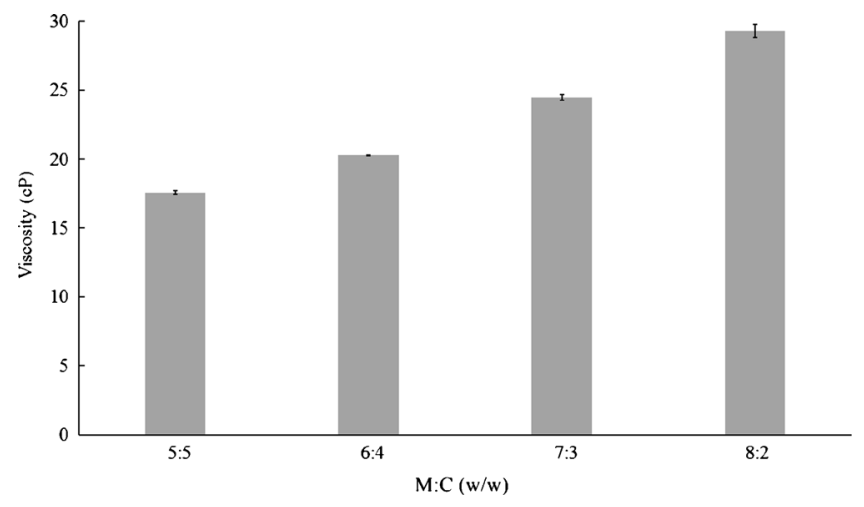

Fig. 1. Viscosity of $\mathrm{M} / \mathrm{C}$ eutectic systems at different ratios $(w / w)(n=3)$. $5: 5$ is the same as $1: 1$ in the content

\section{Statistical Analysis}

Statistical significance of the experiment was examined using one-way analysis of variance (ANOVA) followed by the least significant different (LSD) post hoc test. The significant level was set at $p<0.05$. The analysis was performed using SPSS for Windows.

\section{RESULTS AND DISCUSSION}

\section{Preparation of Eutectic Solvent}

The systems containing 1:1, 6:4, 7:3, and 8:2 M/C were liquid eutectic at room temperature. The ratios of $1: 9$ to $4: 6 \mathrm{M} /$ $\mathrm{C}$ were exhibited the mixture of liquid eutectic and solid content of camphor while the ratio of 9:1 M/C was exhibited the liquid eutectic and solid content of menthol. The viscosity of the liquid eutectics is shown in Fig. 1. All liquid eutectics exhibited Newtonian flow. The statistical analysis result showed that the viscosity of all samples was significantly

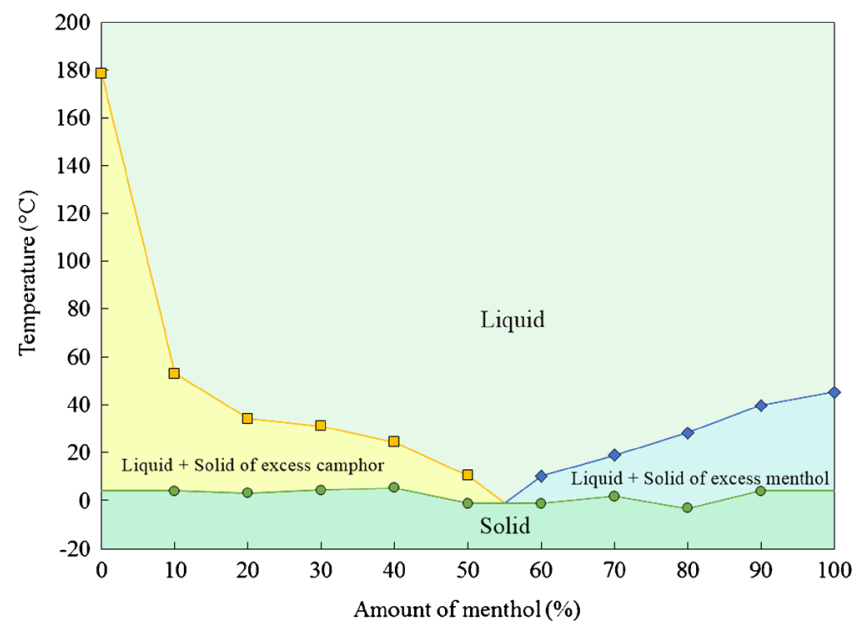

Fig. 2. Phase diagram of menthol and camphor eutectic system. Yellow and blue lines: the melting point of excess camphor and menthol in eutectic system, respectively. Yellow and blue zones: the mixture of liquid eutectic and excess solid of camphor or menthol, respectively. Green line: the melting point of eutectic system. Light blue zone: the liquid state of melted eutectic system. Green zone: the solid state of eutectic system and each excess solid 


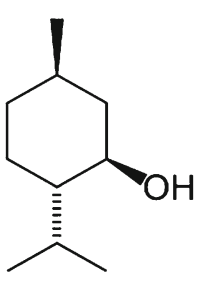

Menthol

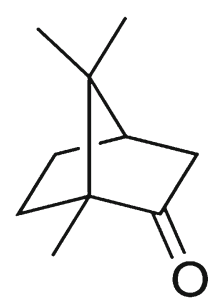

Camphor<smiles>CC(C)Cc1ccc(C(C)C(=O)O)cc1</smiles>

Ibuprofen

Fig. 3. Chemical structures of menthol, camphor, and ibuprofen

different $(p<0.05)$. The 1:1 M/C showed the lowest viscosity, and this system had been used as solvent or co-solvent for the NSAIDs (28-30). This liquid eutectic system (1:1 M/C) was selected as eutectic solvent in this research.

\section{Phase Diagram of M/C Eutectic System}

The DSC data have been used to investigate the thermal properties. The melting point of menthol and camphor powders was 47.82 and $177.33^{\circ} \mathrm{C}$, respectively, and gradually decreased when the ratio of $\mathrm{M} / \mathrm{C}$ closed to $1: 1$. The simple phase diagram of $\mathrm{M} / \mathrm{C}$ eutectic system is shown in Fig. 2. The yellow and blue lines were the melting point of excess camphor and menthol in eutectic system, respectively. The yellow and blue zones were the mixture of liquid eutectic and excess solid of camphor or menthol, respectively. The green line was the melting point of eutectic system. The light blue zone was the liquid state of melted eutectic system, and the green zone was the solid state of eutectic system and each excess solid. The eutectic point and eutectic temperature of menthol and camphor eutectic system were between 50 and $60 \%$ menthol and $-1^{\circ} \mathrm{C}$, respectively.

\section{Water Solubility of Ibuprofen and Ibuprofen Eutectic Solution}

From HPLC analysis, the retention time of ibuprofen was $12.85 \pm 0.30 \mathrm{~min}$. The standard equation of ibuprofen was $y=$ $1446.5 x+21.678$ with $r^{2}=0.9992$ in the range of $0.2-$ $1.2 \mathrm{mg} \mathrm{mL}^{-1}$ which the analysis was passed for method validation. Solubility of ibuprofen in 1:1 M/C was 282.11 $6.67 \mathrm{mg} \mathrm{mL}^{-1}$. The amounts of solubilized ibuprofen in water of ibuprofen powder and ibuprofen eutectic solution were
$9.81 \pm 2.71$ and $40.4 \pm 8.8 \mu \mathrm{g} \mathrm{mL}^{-1}(n=3)$, respectively. Therefore, this eutectic solvent could enhance the drug solubility in water by about fourfold which is higher than that of the previous report (6).

\section{FTIR-HATR Analysis}

The chemical structures of menthol, camphor, and ibuprofen are shown in Fig. 3. From the obtained IR spectra, menthol exhibited the $\mathrm{O}-\mathrm{H}$ stretching of hydroxyl group at $3261 \mathrm{~cm}^{-1}$ whereas camphor exhibited the $\mathrm{C}=\mathrm{O}$ stretching of carbonyl group at $1742 \mathrm{~cm}^{-1}$ while the eutectic solvent exhibited the $\mathrm{O}-\mathrm{H}$ stretching of menthol at $3422 \mathrm{~cm}^{-1}$ and exhibited the $\mathrm{C}=\mathrm{O}$ stretching of camphor at $1742 \mathrm{~cm}^{-1}$ as shown in Fig. 4. Ibuprofen exhibited the carboxyl group of $\mathrm{C}=\mathrm{O}$ stretching at $1732 \mathrm{~cm}^{-1}$ and $\mathrm{C}-\mathrm{H}$ stretching and $\mathrm{O}-\mathrm{H}$ stretching at 2800 to $3200 \mathrm{~cm}^{-1}$, respectively. The IR spectra of ibuprofen eutectic solution showed the same pattern as the eutectic solvent because the spectra of ibuprofen overlapped with those of menthol and camphor as shown in Fig. 4. This indicated that ibuprofen dissolved or melted in the eutectic solvent which did not exhibit a chemical reaction with eutectic solvent. However, the eutectic system of ibuprofen-terpene compound (menthone, menthol, thymol, and cineole) exhibited the shift of $\mathrm{C}=\mathrm{O}$ stretching of ibuprofen indicating the hydrogen bonding of ibuprofen and terpene compound (4).

The most eutectic phenomenon was reported as the hydrogen bonding of the hydroxyl group in small molecules with the carbonyl group in another molecule $(4,12)$. The $\mathrm{O}-\mathrm{H}$ stretching of menthol in eutectic system at ratios of $1: 9$ to $1: 1$ $\mathrm{M} / \mathrm{C}$ showed a constant wave number of $3422 \mathrm{~cm}^{-1}$. For the ratios of $6: 4$ to $9: 1$, the $\mathrm{O}-\mathrm{H}$ stretching of menthol gradually

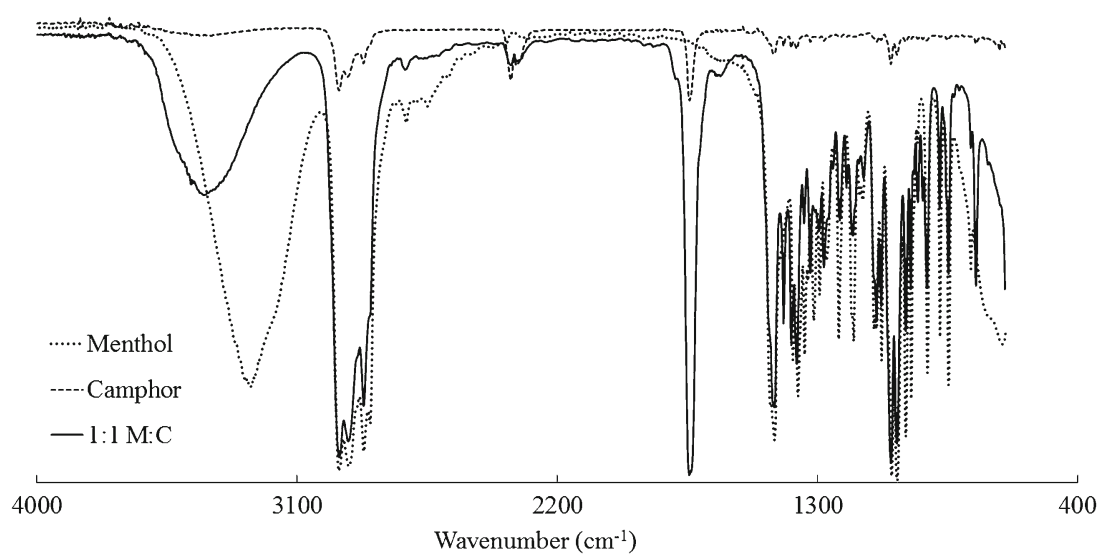

Fig. 4. FTIR spectra of menthol, camphor, and eutectic system of $1: 1 \mathrm{M} / \mathrm{C}$ 


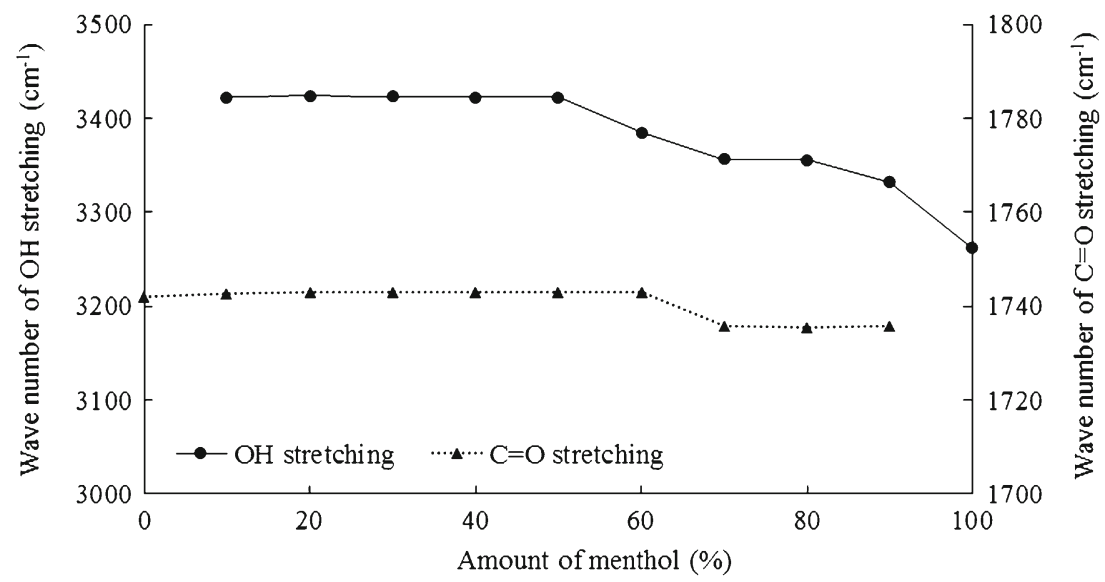

Fig. 5. Wave number of $\mathrm{O}-\mathrm{H}$ stretching of system comprising various ratios of menthol and camphor

decreased to 3332 and $3261 \mathrm{~cm}^{-1}$ for menthol powder as shown in Fig. 5. This result represented the hydrogen bonding of hydroxyl group of menthol and carbonyl group of camphor. At the ratios of 1:9 to $1: 1 \mathrm{M} / \mathrm{C}$, menthol completely formed the eutectic system with camphor; thus, the wave number of $\mathrm{OH}$ stretching was constant and the wave number decreased when the menthol was more than $50 \%$, indicating the excess amount of menthol to form the eutectic system with camphor $(4,12)$. This result notably supported the DSC data which indicated the eutectic point of the menthol-camphor eutectic system at around $1: 1 \mathrm{M} / \mathrm{C}$.

In case of $\mathrm{C}=\mathrm{O}$ stretching of camphor, the wave number of $\mathrm{C}=\mathrm{O}$ stretching of $9: 1$ to $7: 3 \mathrm{M} / \mathrm{C}$ was $1735 \mathrm{~cm}^{-1}$ which shifted from $1742 \mathrm{~cm}^{-1}$ of camphor powder and other ratios as presented in Fig. 5. This result confirmed that menthol and camphor formed the hydrogen bonding in liquid eutectic mixture. The wave number shift for the $\mathrm{C}=\mathrm{O}$ stretching of carbonyl group to a lower wave number has been reported to indicate a hydrogen bonding formation of the hydroxyl group and carbonyl group $(4,8)$.

\section{Thermal Analysis}

A DSC thermogram of ibuprofen showed a sharp melting endothermic peak at $77.83^{\circ} \mathrm{C}$. The lower saturated $(20 \% \mathrm{w} / \mathrm{w})$, saturated $(30 \% \mathrm{w} / \mathrm{w})$, and oversaturated concentrations $(50 \%$ $w / w)$ of ibuprofen in eutectic solvent were investigated. For this experiment, the three levels of ibuprofen concentration were selected to investigate the melting property of ibuprofen in $1: 1 \mathrm{M} / \mathrm{C}$. The $20 \% \mathrm{w} / \mathrm{w}$ ibuprofen was selected as the nonsaturation concentration. However, in case of non-saturation concentration, ibuprofen completely dissolved and the DSC thermogram of all concentrations in range of non-saturation level was not different; thus, this concentration was selected for this study. The $30 \% w / w$ ibuprofen was selected as the saturated concentration in 1:1 M/C. The $50 \% \mathrm{w} / \mathrm{w}$ ibuprofen was the higher concentration than saturation concentration which was selected for investigation of the melting behavior of ibuprofen in 1:1 M/C. In the case of the oversaturated concentration, the DSC thermogram showed a broad endothermic peak at $49.53^{\circ} \mathrm{C}$; onset at $27.57^{\circ} \mathrm{C}$ indicated a suppression of ibuprofen melting point. Whereas, there was no endothermic peak in the lower saturated and saturated concentrations of ibuprofen because the ibuprofen was completely melted as shown in Fig. 6. Therefore, ibuprofen could occur within the eutectic phenomenon $(4,24)$ with eutectic solvent but did not form a chemical reaction.

The weight loss under heat condition with open system was investigated using TGA. The temperature exhibiting the highest rate of weight loss was indicated by a peak in the differential thermogravimetric analysis (DTGA) data. Menthol, camphor, and eutectic solvent showed similar weight loss patterns with being one step as shown in Fig. 7. The weight loss of menthol and camphor related to the evaporation and sublimation, respectively. The weight loss of all test samples started and ended at about 108 and $170^{\circ} \mathrm{C}$, respectively, and the highest rate of weight loss was in the range of 144.97 to $148.59^{\circ} \mathrm{C}$ as shown in Table I. The weight loss rate was the highest for 1:1 $\mathrm{M} / \mathrm{C}$ because the viscosity of this liquid was lower than the other mixtures as shown in Fig. 1. The mass transfer from consistent viscous liquid into gas state owing to evaporation process is typically more difficult than that from less viscous one (31).

TGA was aimed to study the ibuprofen degradation or evaporation in the form of eutectic system; thus, the concentration lower than saturation concentration was selected to make sure that the drug was completely dissolved in the eutectic system. TGA thermogram of ibuprofen and 20\% w/ $w$ ibuprofen eutectic solution are shown in Fig. 7. The weight loss started and ended at 205.16 and $273.35^{\circ} \mathrm{C}$, respectively. The highest rate of weight loss was at $247.70^{\circ} \mathrm{C}$ as shown in

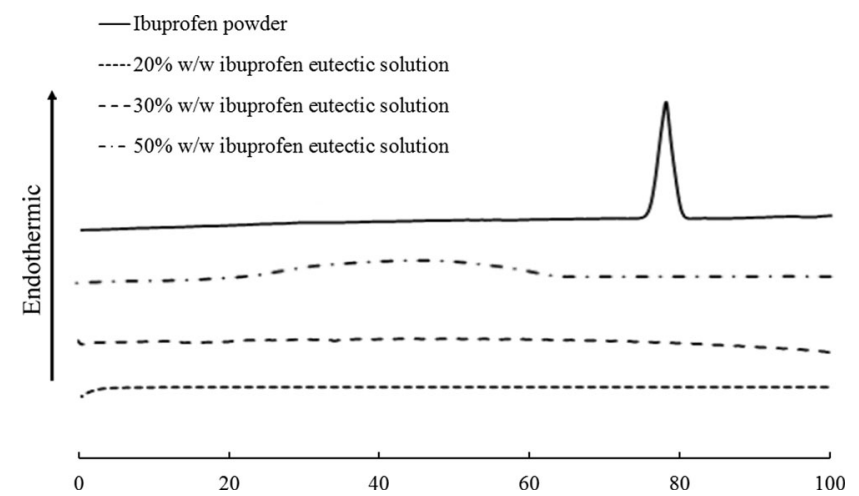

Fig. 6. DSC thermograms of ibuprofen powder and ibuprofen eutectic solutions 


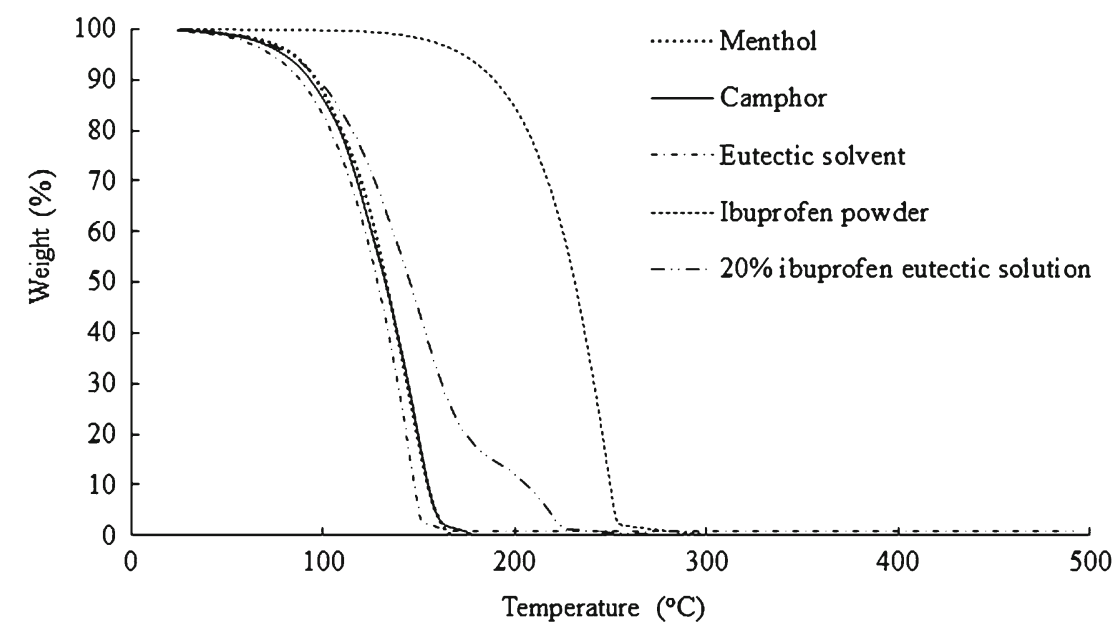

Fig. 7. TGA thermograms of ibuprofen, eutectic solvent, and ibuprofen eutectic solution

Table I which showed the same trend as a previous work that the evaporation of ibuprofen started at about $190^{\circ} \mathrm{C}$ and ended at $277^{\circ} \mathrm{C}$ and the DTGA peak was at $255^{\circ} \mathrm{C}$ (32).

The $20 \% \mathrm{w} / \mathrm{w}$ ibuprofen eutectic solution had two steps of weight loss with the first step being eutectic solvent evaporation and the next step being ibuprofen evaporation as shown in Fig. 7. The weight loss started and ended, and the highest rate of weight loss and weight loss rate of each step are presented in Table I. The onset temperature of ibuprofen evaporation from this eutectic solution was about $3^{\circ} \mathrm{C}$ lower than ibuprofen powder. The evaporation behavior of ibuprofen eutectic solution changed, and the complete weight loss temperature decreased by about $43^{\circ} \mathrm{C}$ because ibuprofen completely formed the eutectic with eutectic solvent and liquefied.

\section{Sublimation or Evaporation Rates}

Both menthol and camphor are sublimate substances; therefore, their eutectic systems (eutectic solvent and ibuprofen eutectic solution) should be the volatile liquids. Sublimation of ibuprofen powder at any employed experimental temperatures was negligible $\left(0.03 \pm 0.02 \mathrm{mg} \mathrm{h}^{-1} \mathrm{~cm}^{-2}\right.$ at $35^{\circ} \mathrm{C}$ to $0.06 \pm 0.03 \mathrm{mg} \mathrm{h}^{-1} \mathrm{~cm}^{-2}$ at $\left.65^{\circ} \mathrm{C}\right)$, but the melted ibuprofen exhibited evaporation rate of $0.12 \pm 0.03 \mathrm{mg} \mathrm{h}^{-1} \mathrm{~cm}^{-2}$ at $85^{\circ} \mathrm{C}$ (Fig. 8). The sublimation or evaporation rates of all substances were higher at elevated temperature. Menthol demonstrated apparently a lower sublimation rate than camphor because the vapor pressure of menthol is lower and a molecule of menthol has hydroxyl group that forms hydrogen bonding with other menthol molecules. The molecular weight of menthol (156.27 $\mathrm{g} \mathrm{mol}^{-1}$ ) was higher than camphor (152.23 $\mathrm{g} \mathrm{mol}^{-1}$ ), and the vapor pressure of menthol $\left(0.064 \mathrm{mmHg}\right.$ at $\left.25^{\circ} \mathrm{C}\right)$ was notably lower than camphor $\left(0.65 \mathrm{mmHg}\right.$ at $\left.25^{\circ} \mathrm{C}\right)$. The evaporation rate of eutectic solvent was lower than the sublimation rate of camphor but higher than that of menthol. The evaporation rate of the ibuprofen eutectic solution was lower than that of the eutectic solvent because ibuprofen did not sublimate or evaporate in this condition and the more the amounts of non-evaporated molecules, the more the interference for the evaporation rate. However, all systems exhibited dramatically the lower rate than water that exhibited the evaporation rate of $14.23 \pm 0.43 \mathrm{mg} \mathrm{h}^{-1} \mathrm{~cm}^{-2}$ at $35^{\circ} \mathrm{C}$ to $170.57 \pm 12.29$ $\mathrm{mg} \mathrm{h}^{-1} \mathrm{~cm}^{-2}$ at $85^{\circ} \mathrm{C}$.

\section{Evaporation Rate of $M$ and $C$ from Eutectic Solvent from GC Analysis}

Retention times from GC analysis of menthol and camphor were 9.5 and $8.5 \mathrm{~min}$, respectively. The standard curve equation of menthol was $y=0.3441 x-2.3121$ with $r^{2}=0.9997$ in the range $20-750 \mu \mathrm{g} \mathrm{mL}^{-1}$, and the standard curve equation of camphor was $y=0.3364 x-2.4046$ with $r^{2}=0.9997$ in the range 20-750 $\mu \mathrm{g} \mathrm{mL}^{-1}$ which passed the method validation test. The evaporation rates of menthol and camphor were $0.054 \pm 0.005$ and $0.085 \pm 0.003 \mathrm{mg} \mathrm{h}^{-1} \mathrm{~cm}^{-2}$, respectively. Camphor exhibited a higher evaporation rate as previously mentioned, and the evaporation rates of menthol and camphor were different.

Table I. TGA Parameters of Menthol, Camphor, and Eutectic Systems

\begin{tabular}{lccc}
\hline Sample & Onset temperature $\left({ }^{\circ} \mathrm{C}\right)$ & $100 \%$ weight loss temperature $\left({ }^{\circ} \mathrm{C}\right)$ & Peak of DTGA $\left({ }^{\circ} \mathrm{C}\right)$ \\
\hline Camphor & 108.35 & 171.99 & 148.59 \\
$5: 5 \mathrm{M} / \mathrm{C}$ & 108.17 & 168.88 & 147.68 \\
$6: 4 \mathrm{M} / \mathrm{C}$ & 108.92 & 162.67 & 1.74 \\
$7: 3 \mathrm{M} / \mathrm{C}$ & 108.58 & 167.11 & 1.43 \\
$8: 2 \mathrm{M} / \mathrm{C}$ & 108.99 & 174.90 & 1.16 \\
Menthol & 108.44 & 164.27 & 1.98 \\
\hline
\end{tabular}




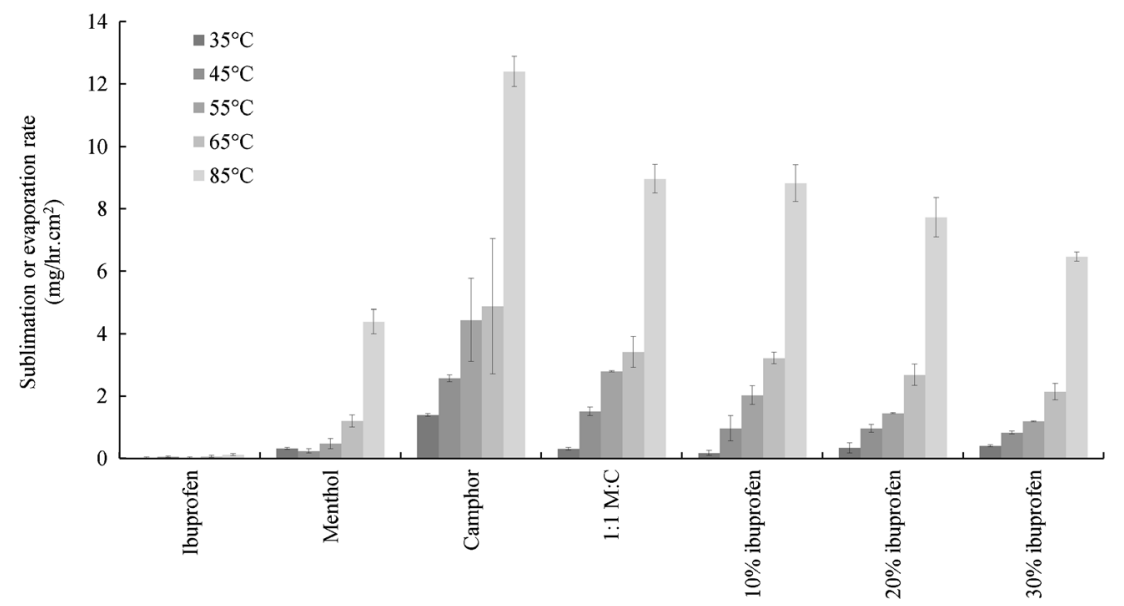

Fig. 8. Sublimation or evaporation rates of different substances at various temperatures $(n=3)$

\section{Release Kinetic of Ibuprofen from Eutectic Solution}

The eutectic solution of $10 \% \mathrm{w} / \mathrm{w}$ ibuprofen in eutectic solvent exhibited Newtonian's flow behavior with the viscosity of $30.80 \pm 1.03 \mathrm{cPs}$. The in vitro drug release from the eutectic solution with dialysis tube method is shown in Fig. 9 which the $54.78 \pm 0.63 \%$ drug released was found at $152 \mathrm{~h}$. The released mechanism was Higuchi's model which is the best fitting $\left(r^{2}=\right.$ $0.9865, \mathrm{msc}=4.09)$. Therefore, the drug release from eutectic solution was diffusion control. The prolonged release of ibuprofen from eutectic solution could be suitable for periodontitis treatment with combination with antibiotic into periodontal pocket to reduce the administration time. This eutectic mixture was successful as solvent of low-dose drug such as captopril for obtaining homogenous drug content uniformity in capsule and tablet which an ex vivo permeation of captopril was faster and increased (20). Therefore, this eutectic mixture could be applied for many different purposes. For our further research work, this drug eutectic solution will be investigated as internal phase of emulsion for nanosuspension preparation fabricated with emulsion solvent evaporation technique. The rather low evaporation of eutectic mixture will be beneficial for investigation and tracking the mechanism of transformation from nanoemulsion into nanosuspension.

\section{CONCLUSION}

The phase diagram of M/C eutectic system was attained. The eutectic system comprising menthol and camphor was liquid at room temperature for systems containing 50 to $80 \%$ $w / w$ menthol which its eutectic point was near to $50 \% \mathrm{w} / \mathrm{w}$ menthol and the eutectic temperature was $-1^{\circ} \mathrm{C}$. FTIR results indicated the hydrogen bonding of hydroxyl group and carbonyl group in the $\mathrm{M} / \mathrm{C}$ eutectic system. The evaporation rate of menthol from the eutectic solvent was lower than that of camphor. Ibuprofen could melt in eutectic solvent because the eutectic suppressed the melting point of ibuprofen. The ibuprofen eutectic solution exhibited higher water solubility than the ibuprofen powder. The sublimation or evaporation rates of menthol, camphor, eutectic solvent, and ibuprofen eutectic solution were increased with an elevated temperature. This

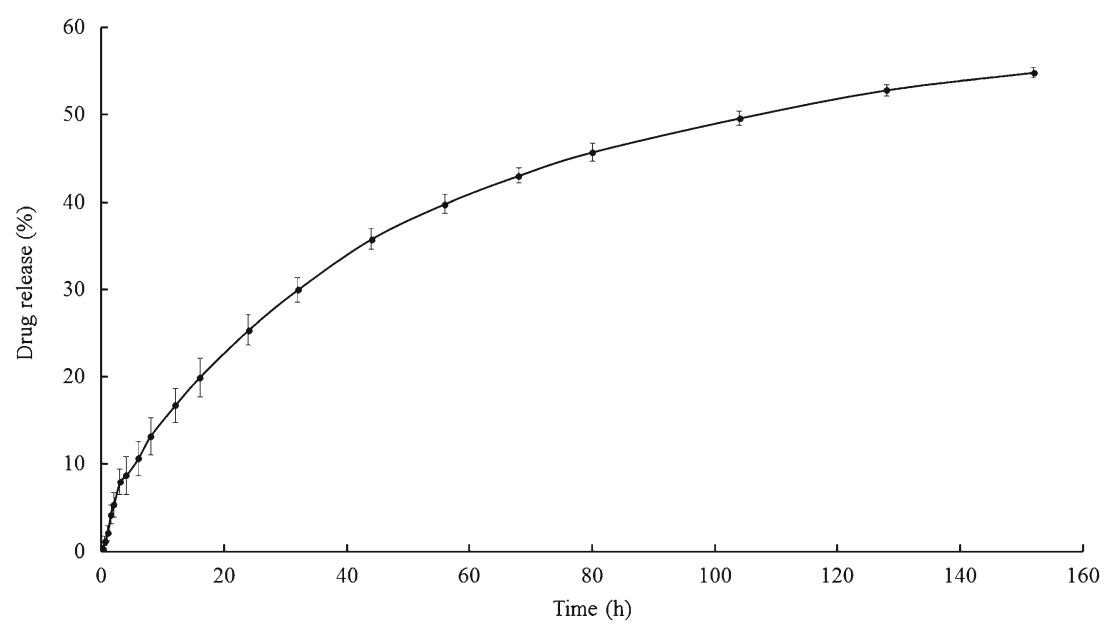

Fig. 9. Drug release profile of ibuprofen from eutectic system $(n=3)$ 
eutectic solvent prolonged the ibuprofen release with diffusion control. Thus, the useful data for thermal behavior and related properties of eutectic solvent and ibuprofen eutectic solution were attained successfully. The evaporation behavior of eutectic solvent will be further applied for nanosuspension preparation with emulsion solvent evaporation technique using eutectic mixture as oil phase.

\section{ACKNOWLEDGMENTS}

This research work was kindly supported by the Faculty of Pharmacy, Silpakorn University. Grant was supported by the National Nanotechnology Center, National Science and Technology Development Agency (Grant P-11-00226).

\section{REFERENCES}

1. Bi M, Hwang SJ, Morris KR. Mechanism of eutectic formation upon compaction and its effects on tablet properties. Thermochim Acta. 2003;404:213-26.

2. Woolfson A, Malcolm R, Campbell K, Jones D, Russell J. Rheological, mechanical and membrane penetration properties of novel dual drug systems for percutaneous delivery. J Control Release. 2000;67:395-408.

3. Lazerges M, Rietveld I, Corvis Y, Céolin R, Espeau P. Thermodynamic studies of mixtures for topical anesthesia: lidocaine-salol binary phase diagram. Thermochim Acta. 2010;497:124-8.

4. Stott P, Williams A, Barry B. Transdermal delivery from eutectic systems: enhanced permeation of a model drug ibuprofen. J Control Release. 1998;50:297-308.

5. Stott P, Williams A, Barry B. Mechanistic study into the enhanced transdermal permeation of a model $\beta$-blocker; propranolol; by fatty acids: a melting point depression effect. Int J Pharm. 2001;219:161-76.

6. Yong C, Oh Y, Jung S, Rhee J, Kim H, Kim C, et al. Preparation of ibuprofen-loaded liquid suppository using eutectic mixture system with menthol. Eur J Pharm Sci. 2004;23:347-53.

7. Nazzal S, Smalyukh I, Lavrentovich O, Khan M. Preparation and in vitro characterization of a eutectic based semisolid selfnanoemulsified drug delivery system (SNEDDS) of ubiquinone: mechanism and progress of emulsion formation. Int J Pharm. 2002;235:247-65.

8. Dominguez de Marı P, Maugeri Z. Ionic liquids in biotransformations: from proof-of-concept to emerging deep-eutectic-solvents. Curr Opin Chem Biol. 2011;15:220-5.

9. Lindberg D, Revenga M, Widersten M. Deep eutectic solvents (DESs) are viable cosolvents for enzyme-catalyzed epoxide hydrolysis. J Biotechnol. 2010;147:169-71.

10. Miller R. Deep eutectic solvents and applications. 2009, US 20090247432.

11. Morrison H, Sun C, Neervannan S. Characterization of thermal behavior of deep eutectic solvents and their potential as drug solubilization vehicles. Int J Pharm. 2009;378:136-9.

12. Chun-Woong P, Heidi M, Tack-Oon O, Ju-Young K, Jung-Myung $\mathrm{H}$. Phase behavior of itraconazole-phenol mixtures and its pharmaceutical. Int J Pharm. 2012;436:652-8.
13. Kang L, Juna H, McCall J. Physicochemical studies of lidocainementhol binary systems for enhanced membrane transport. Int $\mathbf{J}$ Pharm. 2000;206:35-42.

14. Liu J, Fu S, Wei N, Hou Y, Zhang X, Cui H. The effects of combined menthol and borneol on fluconazole permeation through the cornea ex vivo. Eur J Pharmacol. 2012;688:1-5.

15. Lazerges M, Corvis Y, Pardieu E, Bouteiller L, Espeau P. Excess properties of the salol/lidocaine eutectic liquid mixture: thermodynamic and spectroscopic investigations. Fluid Phase Equilib. 2012;315:107-12.

16. Corvis Y, Espeau P. Incidence of chirality on the properties of mixtures containing an amide type anesthetic compound. Thermochim Acta. 2012;539:39-43.

17. Tuntarawongsa S, Phaechamud T. Menthol, borneol, camphor and WS-3 eutectic mixture. Adv Mater Res. 2012;560:355-8.

18. Patel T, Ishiuji Y, Yosipovitch G. Menthol: a refreshing look at this ancient compound. J Am Acad Dermatol. 2007;57:873-8.

19. Al-Bayati F. Isolation and identification of antimicrobial compound from Mentha longifolia L. leaves grown wild in Iraq. Ann Clin Microbiol Antimicrob. 2009;8:20. doi:10.1186/14760711-1188-1120.

20. Gohel MC, Nagori SA. Resolving issues of content uniformity and low permeability using eutectic blend of camphor and menthol. Indian J Pharm Sci. 2009;71:622-9. doi:10.4103/0250474X.59543.

21. Dario R, Grenier A, Alberti I, Rogue C, Besse C, Laetitia H. Pharmaceutical compositions with melting point depressant agents and method of making same. 2007, US 20070048360 A1.

22. Tuntarawongsa S, Phaechamud T. Application of eutectic solvent to preparation of ibuprofen suspension by emulsion evaporation method. Adv Mater Res. 2015;1060:188-91.

23. Aroso IM. Craveiro R, Rocha Â, Dionísio, M, Barreiros S, Reis RL, et al., 2015. Design of controlled release systems for THEDES - therapeutic deep eutectic solvents, using supercritical fluid technology. Int J Pharm. 2015;492:73-9. doi:10.1016/ j.ijpharm.2015.06.038.

24. Liu Z, Shao Y, Yin C, Kong Y. Measurement of the eutectic composition and temperature of energetic materials. Part 1 . The phase diagram of binary systems. Thermochim Acta. 1995;250:65-76.

25. Ramesha S, Shantib R, Morris E. Studies on the plasticization efficiency of deep eutectic solvent in suppressing. Carbohydr Polym. 2012;87:701-6.

26. Kangthong S, Honghiranruang W, Khejonnit A. Validation of GC method for the determination of camphor and menthol in body powder. Bull Dept Med Sci. 2003;45:198-211.

27. MicroMath, Scientist 3.0 by MicroMath getting started guide. 2006, MicroMath, USA.

28. Biswal B, Karna N, Nayak J, Joshi V. Formulation and evaluation of microemulsion based topical hydrogel containing lornoxicam. J Appl Pharm Sci. 2014;4:77-84.

29. Tyagi S, Panda A, Khan S. Formulation and evaluation of diclofenac diethylamine microemulsion incorporated in hydrogel. World J Pharm Res. 2012;1:1298-319.

30. Gohel M, Nagori S. Fabrication and evaluation of hydrogel thickened microemulsion of ibuprofen for topical delivery. Indian J Pharm Educ Res. 2010;44:189-96.

31. Kabova Y, Kuznetsov VV, Kabov O, Gambaryan-Roisman T, Stephan P. Evaporation of a thin viscous liquid film sheared by gas in a microchannel. Int J Heat Mass Transf. 2014;68:527-41.

32. Xu F, Sun L, Tan Z, Liang J, Li R. Thermodynamic study of ibuprofen by adiabatic calorimetry and thermal analysis. Thermochim Acta. 2004;412:33-7. 